\title{
Health Capacity Development Through Telemedicine in Africa
}

\author{
M. Mars \\ Department of TeleHealth, Nelson R Mandela School of Medicine, University of KwaZulu-Natal, South Africa
}

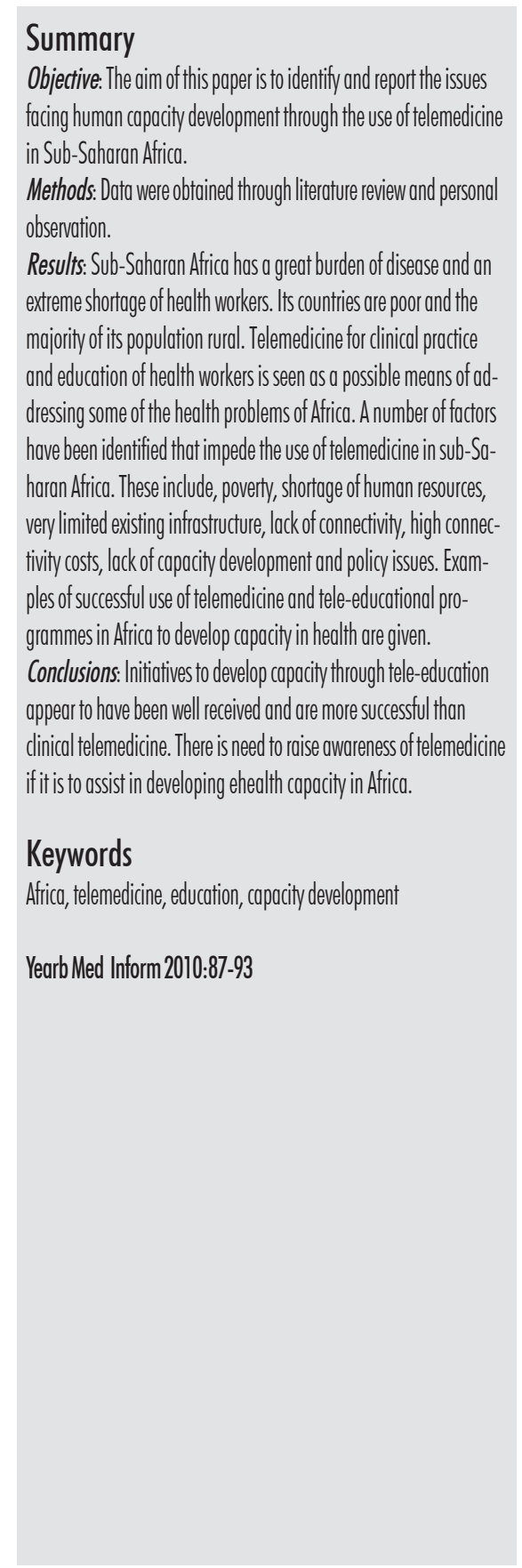

Africa, and in particular sub-Saharan Africa faces many challenges; extreme poverty, a disproportionate burden of disease, rapid population growth, a shortage of skilled human resources, and irregular or absent power supply. Its health problems were succinctly summarised in the World Health Organization (WHO) World Health Report of 2006, "...Africa has $24 \%$ of the burden (of disease), but only $3 \%$ of the health workers commanding less than $1 \%$ of world health expenditure." and "The exodus of skilled professionals in the midst of so much unmet health needs places Africa at the epicentre of the global health workforce crisis." [1].

eHealth, is seen as a possible way of addressing some of these health problems. Resolution WHA58.28 of the World Health Assembly of 2005 called on member nations to develop long term ehealth strategic plans, provide necessary telecommunications infrastructure for ehealth and establish national centres of excellence [2]. The WHO Global Observatory for eHealth report of 2006 suggested that, "It may be time to put forth the concept of 'eHealth for all by 2015 ' as an addendum to the Millennium Development Goals." it also noted the need for an international knowledge exchange network to share practical experiences on the application and impact of ehealth initiatives, the use of elearning programmes and the inclusion of ehealth courses within university curricula [3].

The World Health Organization has defined ehealth as "the combined use of electronic communication and information technology in the health sector".
Telemedicine is a component of ehealth. The International Society for Telemedicine and eHealth defines telemedicine as the, "delivery of healthcare services, where distance is a critical factor, by all healthcare professionals using information and communications technologies for the exchange of valid information for diagnosis, treatment and prevention of disease and injuries, research and evaluation, and for the continuing education of healthcare providers, all in the interest of advancing the health of individuals and their communities." [4]. Clinical telemedicine covers three areas, store and forward or asynchronous tele-medicine in which data are transmitted to a health practitioner who responds at a convenient time, interactive or synchronous telemedicine which is largely videoconference or telephony based and remote monitoring. Tele-education may be videoconference or Web based. As telemedicine is information and communications technology (ICT) based it is dependent on adequate infrastructure and support, among other things, for its successful use.

Despite the seemingly obvious benefits to be gained through efficient use of telemedicine its uptake in sub-Saharan Africa has been very low. One reason is the shortage of human resources and the lack of capacity development in telemedicine in Africa, but there are many others, including access to infrastructure, ignorance, heavy workload and cost.

How can telemedicine develop capacity in health? The use of telemedicine in clinical practice requires some 
form of training and capacity development of the practitioners involved. Clinical practice of telemedicine has been shown to develop clinical capacity in the practitioners at the referral site [5]. Capacity is also developed by tele-education using information and communication technologies ICT for training and continuing professional development of health practitioners.

This paper will provide an overview of factors in Africa which have an impact on the implementation and use of telemedicine and thus capacity development and will describe some of the major telemedicine programmes, both clinical and educational, in place in subSaharan Africa.

\section{Sub-Saharan Africa - the Environment}

All of the 48 sub-Saharan African countries are developing nations. The term "developing" is unfortunate, because it aggregates a wide spectrum of economies, from the poorest of the poor to emerging nations. The term, "the bottom billion" has been used to describe the poorest of the poor, many of whom reside in sub-Saharan Africa [6]. It is these people, many of whom are rural nomadic herdsmen and subsistence farmers, who are most in need of the potential benefits of the use of ICT in health.

\section{Burden of Disease and Population Dynamics}

The burden of disease is great. Approximately two thirds of all $\mathrm{HIV}^{+}$people live in sub-Saharan Africa [7]. Malaria kills a million people a year worldwide and over $90 \%$ of the half billion new cases of malaria a year, occur in Africa [8]. Tuberculosis and poliomyelitis are re-emerging [7]. While the developed world grapples with the problem of the healthcare costs associated with an ageing population and declining birth rates, the situation in Africa is different. The population of Africa continues to grow rapidly. Of the predicted world population increase of 2.3 billion people by 2050, one billion will be in Africa. Life expectancy for the continent is 54 years [9]. Maternal and infant mortality rates remain high and in the foreseeable future there are going to be a large number of pregnant women and young children, all of whom require skilled medical support. It is unlikely that any African country will meet the three health related Millennium Development Goals, of reduction of infant mortality, maternal mortality and infectious disease by 2015 [10].

\section{Health Workforce}

The shortage of health professionals is extreme. Thirty countries have 10 or fewer doctors per 100,000 people and 37 have fewer than 20 doctors per 100,000 people. In comparison, Germany has 340, the USA has 260, England 230, Canada 190, and India 60, doctors per 100,000 people respectively [7]. Medical practitioners tend to live in urban areas whereas $60 \%$ of Africa's population is rural [11]. Telemedicine offers the potential to overcome this maldistribution and improve access to scarce medical specialists. The reality, however, is that telemedicine adds steps to the normal workflow, increasing the work of already overburdened staff at both the send and receive sites.

It is often forgotten that when there is a shortage of doctors, there are also insufficient doctors to teach new doctors, train medical specialists and provide healthcare professionals with continuing professional education. There are medical schools without specialists in some fields. The same holds true for nurses and other allied medical specialties.

\section{Health Budgets}

With limited health budgets, expectations of the benefits to be derived from ICT in health need to be appropriate: the Governments of 18 countries allo- cate less than US\$ 10 per capita, per annum, for health and 31 countries less than US\$ 20 per capita, [7] A recent small survey of six countries in East, Central and Southern Africa indicated that the average government budget for the use of ICT in health would be US\$ 0.32 per capita per annum, for the next three years compared to US\$ 55 in the USA. The amount is very low but it should be considered as a percentage of a low initial budget.

\section{ICT Provision}

There are unfortunately many factors inhibiting the use of ICT for health in Africa. Power, or rather the absence or irregularity of power is a major problem for most of Africa. While the developed world benefited from widespread provision of cable and bandwidth during the dot.com boom, Africa did not. As a result, bandwidth is both limited and costly and even more so in landlocked countries. Fixed telephone line penetration in Africa is very low, $1.4 \%$, and is a major barrier to Internet access via telephony. This combined with the high cost of bandwidth has limited Internet penetration in sub-Saharan Africa to $4.2 \%$ of the population. Broadband access is a luxury. In 22 African countries an entry level broadband package exceeds the average monthly gross national income per capita. Broadband penetration is about $1 \%$, of which $0.9 \%$ is by mobile phone. While mobile penetration has risen rapidly to $31.8 \%$ it too is expensive. The International Telecommunications Union (ITU) has developed an average cost for mobile use based on a basket of calls to own, other networks and fixed lines during peak and off peak times. This basket of services averages $23 \%(1 \%$ $60 \%)$ of average monthly Gross $\mathrm{Na}$ tional Income (GNI) per capita in Africa. The cost of the same basket in the United States of America (USA) is $0.4 \%$ of monthly GNI per capita. A bundle of services defined by the ITU, fixed phone line, mobile cellular and fixed 
broadband Internet services averaged $41 \%$ (range $3.3 \%-72.4 \%$ ) of average GNI per capita in Africa, against a global average of $15 \%$. In comparison, the same ICT basket constitutes $0.4 \%$ of the average GNI per capita in the USA, $0.7 \%$ in Canada and the United Kingdom and $0.8 \%$ in Germany. The high cost of telecommunication is seen as a major obstacle to the further uptake of ICT on the continent [12-14].

Store and forward telemedicine is a cheap and simple telemedicine solution in the developed world but is expensive in sub-Saharan Africa and may require satellite connectivity in rural areas because of the absence of fixed telephone lines. Synchronous videoconference based telemedicine is even more expensive [15].

\section{Civil War and Unrest}

For various reasons there have been a disproportionately large number of civil wars in Africa with resultant destruction of infrastructure and migration of people. On average, every year of civil war sets a country's economy back by 7 years [6].

\section{Telemedicine Policy and Strategy}

For telemedicine to move from donor funded pilot projects to sustainable services, there needs to be national policy or strategy. Approximately half of the countries in the world have some form of ehealth policy, strategy or roadmap [16]. In sub-Saharan Africa, while several countries are working on policy only four have a current policy. Several countries have yet to even finalise national ICT policies.

There is unfortunately little guidance from the African Union Health Ministers and the New Partnership for Africa's Development (NEPAD) on ehealth. None of their strategies and policy documents of the last 5 years mention ehealth, telehealth or telemedicine $[17,18]$.
An emerging problem is that of false expectation. Policy makers are being sold the concept of telemedicine as a means of solving their shortage of doctors, improving health-worker education and reducing the costs borne by patients who would otherwise have to travel to see specialists. Their expectations of the return on investment are commonly too high. A recent audit of telemedicine use, showed that $58 \%$ of referral sites referred less than one case per site per week and $73 \%$ referred fewer than two cases per site per week [19]. The reality is also that a service can only be provided if doctors buy-in to the process and are adequately remunerated for the extra work.

International humanitarian telemedicine assistance is a possible way of addressing the shortage of specialists in a country. To be widely used, this will require guidelines and legal and ethical frameworks for interjurisdictional practice of telemedicine, which do not exist.

\section{Telemedicine and Capacity Development in Sub- Saharan Africa}

Participation in a clinical telemedicine programmes has been shown to be a form of capacity development [5]. Doctors and nurses at the send site learn from the interaction with the specialist or more knowledgeable peer at the receive site and over time identify and manage conditions that they would previously have referred.

With the financial, infrastructural and human resource constraints described, it is not surprising that clinical telemedicine uptake has been low in Africa. Early pilot projects, such as the teleradiology project in Mozambique, linking two hospitals in Maputo and Beira in the late 1990s and the National Telemedicine Project in South Africa, at the turn of the century both failed. New initiatives have taken place at in- ternational, regional and local levels, examples of which are outlined below.

\section{Pan African e-Network}

The Pan African e-Network, launched in 2004 is a clinical telemedicine and continuing professional development project funded by the Indian Government and supported by the African Union. The health component of the project offers telemedicine and teleeducation services to one teaching hospital and educational site in every African country. These sites will be linked by very small aperture terminal (VSAT) to 5 regional Universities and 5 regional super speciality hospitals in Africa, and 7 Universities and 12 super specialty hospitals in India. The telemedicine component allows each hospital one hour of synchronous telemedicine per day and an asynchronous service for five patients per site per day. These services are free for 5 years. Continuing medical education by videoconference from India is offered in the project, but uptake has been low. It is envisaged that the African Universities and Specialist Hospitals will also provide videoconferenced teaching in their regions and across Africa, but this has not yet happened. To date, 42 countries have joined the project. Tele-education send sites have been established at 3 Universities in India and 3 in Africa (Kwame Nkurumah University of Science and Technology in Ghana, Makerere University in Uganda and Yaounde University in Cameroon). Telemedicine sites have been installed at 9 super specialty hospitals in India and 1 in Africa (Ibadan Super Specialty Hospital, Nigeria) and at one hospital in each of 22 countries. The infrastructure costs, excluding the VSAT and telemedicine equipment is borne by the participating country or University [20]. The issue of future interaction between African sites in this network and other African hospitals and Universities outside of this network has not been resolved. 


\section{RAFT Réseau en Afrique Francophone pour la Télémédecine}

In the Francophone African countries, the RAFT (Réseau en Afrique Francophone pour la Télémédecine) project, based at the Geneva University Hospitals, has been running in Mali since 2001 and is now active in 15 countries. It focuses on interactive distance education. Courses are webcast as presentations and dialogues between experts in different countries. Two one-hour sessions take place each week in French. This has recently been extended with an additional session of an hour each week in English. A feature of the programme is the low bandwidth required to participate; an Internet connection and $30 \mathrm{kbs}^{-1}$ [21]. In rural areas, connectivity is by VSAT which is expensive and limits the expansion of the programme in rural areas. The running cost per health care professional involved in the programme has been calculated as US\$171 per annum [22]. Up to 42 sites connect to these weekly sessions, with 1,200 participants registered [23]. RAFT is an exemplary model for other international collaborative initiatives, but the operating costs remain high. The network has also been used for telemedicine but to a much lesser extent. Use has also been made of the iPath platform for telemedicine and discussion groups.

\section{iPath}

iPath is run by the association TeleMed Basel. It is an open source, web based platform for store and forward clinical telemedicine, discussion groups and education. The iPath web site reports 4,648 active users affiliated to 376 groups. To date, a total of 24,720 cases have been submitted from around the world. From the data provided on the web site, the maximum activity was in May 2008 with nearly 3,700 logins and approximately 560 cases posted. The number of logins is probably skewed by repeat visits in a month and does not represent the number of people who have used the service. Despite this being a free humanitarian service, the number of cases posted remains low, based on the number of active users, logins and groups. The number of African participants is not available, but there are 36 groups, approximately $10 \%$, specifically focused on Africa or African countries. Most of these are in Mali, Tanzania and Burundi, with other groups in Angola, Rwanda, Ethiopia, Cote d'Ivoire, Zimbabwe and South Africa. Activity in each of the groups is not reported [24]. A recent message on the web-site indicates that the future of the iPath platform appears to be uncertain after June 2010.

\section{Swinfen Charitable Trust}

The Swinfen Charitable Trust is an International store and forward tele-medicine service that has been operating since 1999, with 153 hospitals and clinics in 50 countries having used the service. What differentiates it from other store and forward services is that each case is managed on an individual basis by the Trust. This insures that the case is referred to a relevant and competent specialist and that the referral is answered in a timely manner. 1,763 cases were seen between 1999-2008 [25]. Thirteen African countries have used the services of the Trust, but use by African doctors has been low. Data for 2007 show that of the 206 cases referred from 19 countries, only 7 cases were sent from 6 African countries. Of the 6 doctors referring cases from Africa, only one was a local national [26]. The referral service is free but not well utilised by African doctors. Why?

\section{Africa Teledermatology Project}

This store and forward project which began in 2007, offers users free diagnostic and management advice from an international group of experienced colleagues, over the Internet, using the web based telederm.org platform. African participants come from 13 countries. In the first two years of operation 345 cases were referred, which equates to 0.5 cases per country per week [27]. The number of doctors registered to send cases and the number who sent cases is not available. This is another example of the relatively low use of a free service. The project further aims to provide links to educational resources and access to a dermatology curriculum created specifically for African sites, based on the types of cases referred.

\section{Mali IKON Project}

All the radiologists in Mali are based in the capital Bamako. This tele-radiology project links 6 regional hospitals to the capital. Implementation of the project was difficult because of lack of initial buy-in from clinicians at the regional hospitals, the high cost of X-Ray film scanners, lack of bandwidth and the need for VSAT connectivity. In 2006, the first year of full service, 383 $\mathrm{x}$-rays were transmitted, equating to approximately 1 case sent, per site, per week [22]. This has increased to about 1 case per site per day. This project has identified the need to offer regular staff training as in Mali, medical staff stay an average of three to four years at a hospital. Training on the IKON hardware and software is offered every 18 months [28].

\section{South African Telemedicine}

In the State sector, telemedicine services have been devolved to the Provincial Departments of Health, most of which have rudimentary or fledgling services, and in some Provinces the Medical Schools have actively promoted telemedicine. Teleradiology linking CT scanners to a central facility has been successful for many years but the uptake of other forms of telemedicine remains low. Videoconferencing has been 
used successfully for undergraduate and postgraduate teaching and training and continuing professional development. In 2008, the Nelson R Mandela School of Medicine at the University of KwaZulu-Natal broadcast 1,298 hours of interactive videoconferencing covering 32 different academic programmes to its postgraduate students, doctors in rural communities and other medical schools. This is 3.5 hours a day seven days a week. This generated over 95,000 professional development points for the participants (one hour of participation earns one point, per person) for the cumulative total of 35,000 participants. Many of these sessions have been recorded to DVD for distribution to sites without videoconferencing coverage. As a pilot project, DVD's of the Paediatric Surgery seminar programme have been mailed to four other medical school in Africa which do not yet have the infrastructure to link directly to the videoconference sessions. This has proved successful and medical schools in other countries have asked to be included in the project [29].

\section{Other Services}

Remote Access for Health Professionals provides Internet based support and teaching to Ismaili health professionals in Tanzania and Kenya [30]. Medical Missions for Children has a presence in 13 African countries [31]. Orbis Cyber-Sight offers free consultation, education resources and e-Learning [32]. The Children's National Medical Centre in Washington offers a pediatric echocardiography service and health professional training to a hospital in Uganda [31]. ICONS in Health is a new US based humanitarian store and forward telemedicine service and Johns Hopkins provides medical training to Ethiopia. The Evangelical Lutheran Church provides about $15 \%$ of Tanzania's health services through its 20 hospitals, 5 paramedical institutions and 160 dispensaries and health centres. Doctors from 14 hospitals have under- gone training on the use of iPath, digital cameras and i-teach for distance learning [33].

\section{Why Are Free Telemedicine Services Poorly Utilised?}

Limited use of a free service in developing countries has been described by Wootton as "A paradox of altruism". $\mathrm{He}$ posits 5 reasons for this: 'Thatcherism' which he links to the privatization of public services and the perception that people do not value a free service; a cultural problem of asking for help; inappropriate 'experts'; referrers too busy; and perceived loss of control [26]. The issue of culture and the role of Hofstede's Dimensions has not been investigated in the international practice of telemedicine. There are other possible reasons for low utilization. These include: lack of infrastructure; cost of telemedicine including connectivity cost; lack of telemedicine training; and ignorance of telemedicine.

The International Society for Telemedicine and eHealth's (ISfTeH) Basic Telemedicine Training Programme

The ISfTeH has a basic telemedicine training course. It was developed in response to the need to address the general lack of awareness and ignorance of telemedicine among health-workers in both the developed and developing world. In planning the curriculum, the realities of the developing world such as low levels of computer literacy, poor connectivity, poor ICT infrastructure in hospitals and clinics and the general absence of telemedicine programmes were taken in to account. The course is modular, allowing flexibility so that units can be selected and combined to meet the needs of the participating target group. This also allows the course to be spread over several sessions if required. Course delivery is face to face, with didactic lectures supported by ap- propriate readings and course materials, and hands on practical exercises with supporting practical manuals. Over time it is envisaged that some modules may be taken on line with local facilitators overseeing the practical components.

The eleven modules produced include: Introduction to Computers (for those who are not computer literate); Introduction to Telemedicine; Ethics and Law in Telemedicine; Setting Up Venues; Basic Telemedicine Skills; Basic Skills - Use of the Internet; Basic Skills - Use of eMail; Basic Skills digital photography; Practical Use of Store and Forward Telemedicine; Teleeducation; and Telemedicine and Homecare an Introduction. Key strands such as computer skills and ethics in telemedicine thread through all the modules [34]. If taken full-time the course can be completed in two days and for those who are not computer literate, an extra day is required.

The first course was run in Rwanda in 2009 for doctors at the first two hospitals at which the new telemedicine programme will be implemented. Based on the feedback from participants, the structure of the programme has been adapted to alternate practical hands on activities with theory and more case studies will be used than didactic lectures. This initial course was funded by the Africa Telemedicine Fellowship of United Nations Office of Outer Space Affairs [35].

It is planned that additional modules will be developed within specialties such as tele-dermatology, tele-traumatology, tele-radiology, tele-ophthalmology and tele-psychiatry and in areas like telemedicine program planning, implementation and evaluation.

\section{Academic Programmes}

There are very few postgraduate telemedicine training programmes internationally and only one in Africa. The University of KwaZulu-Natal (UKZ-N) offers coursework pro- 
grammes at Postgraduate Diploma (one year post Baccalaureate degree), and Masters level by part -time study. To facilitate access, the courses are offered face to face to local students and by videoconferencing to students outside of the University. Various types of videoconfercencing (VC) have been used, including ISDN based VC in South Africa, IP based desktop VC using either an open source solution, DimDim $^{\circledR}$, or commercial software, Polycom PVX ${ }^{\circledR}$, for students in other countries. When bandwidth has proved to be a problem, students in other countries have been able to participate using Skype with presentations and documents sent to them in advance. An open source learning management system, Moodle has been used for distribution of course materials, submission of assignments, chat rooms, providing feedback to students and course administration.

\section{Other eLearning Initiatives in Health}

The African Medical Research Foundation (AMREF) has developed an eLearning course to assist in retraining and upgrading 22,000 nurses in Kenya in conjunction with the Nursing College of Kenya and the Kenyan Government. Thirty-two medical training colleges and nursing school are part of the programme and 495 computers have been installed in 105 computer training centres. Nurses undergo a mix of face to face sessions, self paced eLearning and 42 weeks of clinical experience, before sitting the Nursing College of Kenya licencing examinations. Similar projects are being planned in Rwanda as part of the Rwandan Health, Education and Information Network (RHEIN) and Uganda.

The Ptolemy Project of the Office of International Surgery at the University of Toronto provides a journal based course for surgical trainees preparing for the Fellowship of the College of Surgery of East Central and Southern Africa available on the web. They pro- vide monthly surgical review papers relevant to the African experience referenced with appropriate full-text online papers and books.

\section{Capacity and Other Issues Related to the Development of Telemedicine}

Who should be trained in telemedicine: patients as the consumers, policy makers, strategic planners, project implementers, health professionals, support staff, and health professional trainees. Apart from isolated reports of telemedicine training, there is little evidence of any significant attempts at human capacity development in telemedicine in Africa. There appears to be the belief that health workers will accept and adopt the technology and the new way of conducting medical practice with minimal support and training. Why is this? In part it can be traced to a lack of understanding of the complexity of the change management process required to implement programmes and systems that alter a long standing status quo and also the failure to budget for change management.

For telemedicine to be successfully integrated into a health system and ultimately into a national health system requires not only support from Government but also understanding of the issues related to the implementation of telemedicine. Key to this is the realisation that there is need for co-operation between several Government Ministries, such as Health, Telecommunications, Education and Science and professional bodies to develop policy and legislation. It is of note that in $13 \mathrm{Eu}-$ ropean Union countries, eHealth policy, strategy or roadmaps, development involved more ministries and stakeholders than the development of Health policy [36].

To date there is no eHealth or Telemedicine legislation in Africa. There is also the need to develop legal and ethical guidelines for the practice of telemedicine both nationally and internationally and to develop, clinical, technical and operational guidelines for the different forms of telemedicine, ranging from static image review in tele-pathology and teleradiology to interactive tele-psychiatry [16].

Development of capacity within Governments is required. Over the past two years there have been a series of meetings bringing together high level stakeholders and Government Ministries in Africa to raise awareness and understanding of telemedicine and ehealth. The Commonwealth Health Ministers Conference in 2008 focussed on ehealth and was followed by Commonwealth Secretariat facilitated meetings in the Seychelles, Kenya, Ghana and Nigeria. The United Nations Office of Outer Space Affairs has held meetings in Tanzania and Burkina Faso and the United Nations Economic and Social Council and the European Space Agency have arranged or collaborated in ehealth conferences.

Unlike Health Informatics which, as a more mature field has many academic programmes developing people for a career in informatics, telemedicine is relatively young and there are few formal academic programmes. The International Society for Telemedicine and eHealth, has identified the need for training, capacity development and raising awareness of telemedicine. It has developed the basic introductory telemedicine training course and is in the process of compiling a database of available formal academic programmes. But are formal University qualifications in telemedicine the solution?

Ideally telemedicine should be an integral part of the practice of medicine, as are the telephone and more recently the fax machine. Students at medical schools and nursing colleges are not taught how to use a phone or a fax machine; they may be told about the ethical and appropriate use of these technologies. Until aspects of telemedicine other than the telephone and 
fax are integrated into service, and their use becomes part of the routine practice of and training in medicine, there will be need for training.

In Africa, while most medical students have access to computers the same is not true in nursing training colleges and many health workers are functionally computer illiterate Cultural issues related to the use of computers and training also come into play. In a study in South Africa, nurses offered a computer literacy course opted to take a pre computer literacy "awareness" course rather than start with hands on training [37].

\section{Conclusions}

The problems facing Africa are great. Telemedicine offers the opportunity to address some of Africa's health issues and develop capacity in the health workforce. The high cost, limited deployment of telecommunications infrastructure, lack of ehealth policy and enabling legislation for telemedicine and the shortage of health professionals are all barriers to the uptake and development of telemedicine in subSaharan Africa. Initiatives to develop capacity through tele-education appear to have been well received and are more successful that clinical tele-medicine. There is need to raise awareness of telemedicine if it is to assist in developing ehealth capacity in Africa.

\section{References}

1. World Health Organization. World health report 2006: working together for health. Geneva: WHO Press; 2006.

2. Committee A. World Health Assembly eHealth Resolution (WHA 58.28). 2005; A58/62:4-6.

3. Building foundations for eHealth. Report of the WHO Global Observatory for eHealth. Geneva: WHO Press; 2006.

4. International Society for Telemedicine and eHealth Glossary of telemedical terms Q-Z. International
Society for Telemedicine and eHealth 2010. http:// www.isft.net/cms/index.php?q_-_z(Accessed on 23 December 2009)

5. Knol A, van den Akker TW, Damstra RJ, de Haan J. Teledermatology reduces the number of patient referrals to a dermatologist. J Telemed Telecare 2006;12:75-8.

6. Collier P. The Bottom Billion. Oxford: Oxford University Press; 2007.

7. World Health Organization. World health statistics 2009. Geneva: WHO Press; 2009.

8. World Health Organization. World malaria report 2009. Geneva: WHO Press; 2009.

9. United Nations DoEaSAPD2. World population prospects. The 2008 revision highlights. Working Paper No ESA/P/WP.210. New York: United Nations; 2009.

10. Achieving the millennium development goals in Africa. Recommendations of the MDG Africa Steering Group June 2008. New York: United Nations Department of Public Information; 2008.

11. United Nations. Rural world population prospects: the 2007 revision. New York: United Nations; 2008.

12. International Telecommunications Union. Information society statistical profiles 2009: Africa. Geneva: 2009. http://www.itu.int/dms_pub/itu-d/ opb/ind/D-IND-RPM.AF-2009-PDF-E.pdf (Accessed on 23 December 2009).

13. International Telecommunications Union. Information society statistical profiles 2009. Americas. 2009. http://www.itu.int/dms_pub/itud/opb/ind/D-IND-RPM.AM-2009-E09-PDF-E.pdf (Accessed 23 December 2009).

14. International Telecommunications Union. Information society statistical profiles 2009. Europe. 2009. http://www.itu.int/dms_pub/itu-d/opb/ind/DIND-RPM.EUR-2009-R1-PDF-E.pdf(Accessed 23 December 2009).

15. World Bank. Information and communication for development (IC4D). Global Trends and Policies. World Bank. 2006.

16. Mars M, Scott RE. Global e-health policy: a work in progress. Health Affairs 2010;29:1-8.

17. Africa health strategy: 2007-2015. 2007;CAMH/ MIN/5(III):1-29.

18. NEPAD. The new partnership for Africa's development (NEPAD) health strategy. Initial programme of action. NEPAD 2009;1-22.

19. Mars M, Scott RE. Teleconsultation usage is limited. Telemed eHealth 2009;15:S46.

20. The Pan-African e-Network Project. http://www. panafricanenetwork.com/Portal/ProjectDetails.jsp? projectidhide $=12 \&$ projectnamehide $=$ Overview (Accessed 23 December 2009).

21. RAFT Network. http://raft.hcuge.ch/ (Accessed 23 December 2009).

22. PriceWaterhouseCoopers. Cost benefit analysis of satellite-enhanced telemedicine and eHealth services in sub-Saharan Africa. European Space Agency 2008;1-157.

23. RAFT general statistics about this server. https:// telemed.ipath.ch/raft/statistics/general (Accessed 23
December 2009).

24. iPath. http://ipath.ch/ipath/ (Accessed 23 December 2009).

25. Swinfen Charitable Trust. http://www. swinfencharitabletrust.org/index.php?option= com_content\&view=article\&id=46\&Itemid=55 (Accessed 23 December 2009).

26. Wootton R. Telemedicine support for the developing world. J Telemed Telecare 2008;14:109-14.

27. Africa Teledermatology project. http:// africa.telederm.org/ (Accessed 23 December 2009).

28. Tanzanian health workshop triggers discussion on challenge and solutions for e-health initiatives. http://www.impactalliance.org/ev02. php?ID=48486_201\&ID2=DO_TOPIC (Accessed 23 December 2009).

29. Mars M. Tele-education in an African country. Global telemedicine and ehealth updates 2009;2:332-6.

30. Remote access for health professionals (RAHP). http://remotehealth.org/index.cfm?Page=About (Accessed 23 December 2009).

31. Alverson DC, Swinfen R, Swinfen P, Rheuban K, Sable C, Smith A et al. Transforming systems of care for children in the global community. Pediatric Annals 2009;38:579-85.

32. Cyber-sight. http://www.orbis.org/Default. aspx?cid=4867\&lang=1 (Accessed 23 December 2009).

33. IICD supported programme: Telemedicine-Tanzania. IICD. http://www.impactalliance.org/ev02. php?ID=48486_201\&ID2=DO_TOPIC (Accessed 23 December 2009).

34. Mars M. The development of an international telemedicine training programme. Telemedicine and eHealth Journal 2008;14:S40.

35. Mars M. The first ISfTeH telemedicine training course Rwanda 2009. Med-e-Tel 2009. http:// www.medetel.lu/download/2009/parallel_sessions/ presentation/day3/eteaching.pdf

36. Hamalainen P, Doupi P, Hypponen H. The European ehealth policy and deployment situation by the end of 2006. Deliverable 2.2 of the eHealth ERA project. 2006;1-187.

37. Krauss K. The collision between international ICT policy and a deep rural Afrocentric community in South Africa: assumptions, interpretation, implementation and reality. Proceedings of the Second Annual SIG GlobDev Workshop 2009;1-37.

Correspondence to:

Prof Maurice Mars

Dept of TeleHealth

Nelson R Mandela School of Medicine

University of KwaZulu-Natal

Pvt Bag 7

Congella 4013

South Africa

Tel: +27 312604543

Fax: + 27312604737

E-mail: mars@ukzn.ac.za 